\title{
APRENDIENDO DE VICO. REFLEXIONES DE CUARENTA AÑOS
}

\section{James Engell \\ (Universidad de Harvard)}

RESUMEN: La filosofía y la retórica (la retórica considerada éticamente, en un espíritu auto-crítico) no son antagonistas, sino aliadas y guías para la vida. La retórica es la corporeización en el lenguaje, y también en otros sistemas semióticos, de lo que motiva a la mayoría de la gente, lo que une lógica y pasión y ética. Una de las esperanzas de Vico es que filosofía y retórica, nuestros poderes racionales e imaginativos, se usen éticamente, para el bien vivir en sociedad. El Autor interpreta la valía del mensaje educacional y social de Vico, cuyo compromiso permanece como algo que ahora -en estos tiempos tecnológicos- necesitamos profundamente.

Palabras ClaVE: Vico, $350^{\circ}$ Aniversario, retórica, educación, época tecnológica, J. Engell.

\section{Learning from Vico. Reflections of forty years}

ABSTRACT: According to the Author's experience, philosophy and rhetoric (rhetoric considered ethically, in a selfcritical spirit) are not antagonists, but allies and guidelines for life. Rhetoric is the embodiment in language, and also in other semiotic systems, of what motivates most people, what unites logic and passion and ethics. One of Vico's hopes is that philosophy and rhetoric, our rational and our imaginative powers, may be used ethically, for the improvement of life in society. The Author interprets the value of the educational and social message of Vico, whose commitments remain something that nowadays - in these technological times - we are in deep need of. KEYwords: Vico, $350^{\text {th }}$ Anniversary, rhetoric, education, technological age, J. Engell.

\section{Imparando da Vico. Quarant'anni di riflessioni}

RIASSUNTO: Filosofia e retorica (retorica considerata eticamente, in uno spirito autocritico) non sono antagonisti, ma alleati e guide per la vita. La retorica è l'incarnazione nel linguaggio, così come in altri sistemi semiotici, di ciò che muove la maggior parte delle persone, di ciò che unisce logica, passione ed etica. Una delle speranze di Vico è che la filosofia e la retorica, i nostri poteri razionali e immaginativi, siano usati eticamente, per il miglioramento della vita in società. L'Autore interpreta il valore del messaggio educativo e sociale di Vico, il cui impegno resta come qualcosa di cui ora -in questi tempi tecnologici- abbiamo profondamente bisogno.

Parole ChiaVe: Vico, $350^{\circ}$ Anniversario, retorica, educazione, epoca tecnologica, J. Engell.

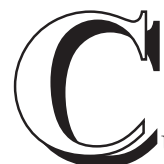

uando leí por vez primera a Vico me sentí confuso -y ocasionalmente aún lo estoy-. Me llevó algunos años, en torno a diez, regresar a su obra y toda-

Este artículo responde a una invitación expresa por parte de la Dirección de la Revista para este volumen especial por el $350^{\circ}$ Aniversario del nacimiento de G. Vico, habiendo superado los criterios de valoración y del proceso de aceptación. 
vía ahora, después de más de cuarenta años de lectura, reflexión, y exámenes de comentarios y criticismo, no puedo sentirme seguro al interpretar a Vico. Él es, para mí, en tiempos provechosamente imprecisos y sugestivos -no realmente ambiguos y ciertamente no sin sentido, pero abiertos, y apelo siempre no solo a nuestra mente racional en sus más estrechos dominios, sino también a nuestras capacidades imaginativas-, al hecho -y es un hecho tanto como cualquier otro hecho es un hechode que nosotros como seres humanos vivimos por encima del entendimiento del mundo natural, de la sociedad y de nuestras propias capacidades. También imaginamos cosas que no existen, combinaciones de palabras que anteriormente no fueron probadas, ideas que no tienen precedentes claros. Descubrimos dimensiones del mundo natural en un sentido empírico, pero también inventamos culturas y narrativas humanas, historias humanas, que en su propio camino tienen todas algo de empírico y poderoso, aunque en cierto modo diferente.

Por esta razón, Vico, desde mi punto de vista, honró a la ciencia como conocimiento sistemático aunque asimismo honró y atrajo la atención de los modernos hacia una ciencia nueva y una retórica nueva -también un nuevo modo de educación-. Sus nuevas empresas consideraron a la sociedad civil como una creación, como una creación auto-actualizante de poderes inventivos de la humanidad. Sí, estos poderes están enredados en conocer la naturaleza y conseguir su dominio sobre ella; sin embargo, estos poderes de auto-reflexión e invención son también los que ayudan a establecer el derecho, las costumbres, los valores, el orden y la belleza. Por esta razón Vico dice que los poetas son los fundadores de la sociedad civil; ellos la crean y la sostienen, una perspectiva de la que Samuel Johnson se hace eco en Rasselas y Percy Shelley en su Defensa de la Poesía. Por poetas, sin embargo, parece que Vico quiere decir no simplemente escritores que emplean el verso o la composición métrica, sino también, y de forma más amplia, escritores y pensadores imaginativos, almas que se abren a la capacidad de los seres humanos para transformarse ellos mismos a través del lenguaje y a través de la manipulación de todos los tipos de signos y símbolos.

La cultura humana es un producto de la maleabilidad de la mente humana y de su capacidad para educar a las más jóvenes generaciones en las realizaciones colectivas de todas las generaciones previas. Esa capacidad, más que cualquier avance específico fisiológico o neurológico con el que la evolución nos ha bendecido, es lo que nos hace humanos. Antropología, etnografía, psicología, semiótica, sociología y el estudio de la mitología: para todas ellas Vico actúa como padrino. Me he topado siempre con que Vico es una figura a horcajadas entre los mundos antiguo y moderno. Toma de los más tempranos estudios del lenguaje y de textos mucho de su propia fundación, y los transforma en una aproximación al conocimiento, educación, y cultura que se adaptan al mundo moderno. 
Las sociedades viven ahora por "big data", social media e investigaciones de mercado, y de muchos modos esto solo refuerza la idea de Vico de que los mitos, los arquetipos y los tópoi están en el corazón de la creencia y el comportamiento humano. Después de todo, ¿qué son los media sociales, sino un espacio virtual donde el lenguaje, la retórica y varios tipos de símbolos y signos -visuales, musicales y más- se acaban en su totalidad, a veces de manera mucho más rápida e intrincadamente que en una cultura impresa?

Los valores prevalentes de una sociedad son de hecho auto-actualizados; aun si se reclaman como revelaciones divinas, deben ser creídas como verdades pertinentes a los humanos, y sobre ellas se debe actuar. Verum factum es un modo de la fe secular en nuestras propias creaciones. Esto lo vio Vico claramente, al igual que también un poeta como William Blake, o novelistas como las hermanas Brontë, o William Faulkner, o Cervantes o Borges. Francis Bacon, quien (según recuerdo) fue uno de los héroes de Vico, supo que la semiótica era una ciencia aún no bien entendida, y también supo que el conocimiento mejorado de la semiótica nos ayudaría a abrir la asombrosa capacidad de los humanos, no solo para representar la naturaleza y el mundo con signos y símbolos, sino también para representar las interacciones humanas con la naturaleza, y también las interacciones entre pueblo y sociedades.

En este sentido, la retórica no es primariamente reglas o la memorización de términos, sino la corporeización en el lenguaje, y también en otros sistemas semióticos, de lo que motiva a la mayoría de la gente, lo que une lógica y pasión y ética. La filosofía y la retórica (la retórica considerada éticamente, en un espíritu auto-crítico) no son antagonistas, sino aliadas. No se necesitan la una a la otra, y además pueden ayudarnos a proporcionarnos una guía para la vida, de cómo vivir.

En todo esto, parece que una de las esperanzas de Vico es que ambas, nuestros poderes racionales e imaginativos, se usen éticamente, para el bien. Todos nosotros hemos visto cómo las sociedades "avanzadas" se pueden pervertir ellas mismas y cómo alguna gente en estas sociedades, y aún líderes de ellas, pueden cometer grandes crímenes, incluso crímenes contra la humanidad. Por ello, una de las cuestiones es ¿cómo podemos identificar y focalizarnos sobre los fines, así como también sobre los medios, especialmente cuando los medios tecnológicos pueden ser tan novedosos y atractivos? ¿Cómo podemos asegurar que los poderes de imaginación y persuasión, de cultura y de creencia, y de maestría tecnológica están orientados a algo que es progresivo, a algo que actualmente mejore las vidas de otros? Es labor muy difícil, siempre un desafío. La visión de Vico de la mente heroica y de la grandeza humana es una llamada para cumplir este desafío.

Hoy, en una época de "responsabilidad" educacional, medida y valoraciones cuantitativas de la investigación, la obra de Vico presenta un especial mensaje para sistemas de educación que son plenamente tentados por las recompensas a 
corto plazo de preparación para la educación, tentados por una producción de conocimiento que servirá solo a los poderes e intereses presentes, más que a apuntar hacia una razón informada, imaginativa, que pueda de hecho servir a aquellos poderes e intereses, pero que desarrollará también una crítica de ellos y los mejorará, también, quizás en última instancia los reemplazará. En pocas palabras, Vico expresa un mensaje educacional y social, y su compromiso permanece como un algo que ahora necesitamos profundamente. ¿Por qué? Las presiones para una enseñanza puramente utilitaria son grandes. La verdad y la utilidad no pueden, no deben ser nunca ignoradas o denigradas; deben seguirse, aunque no ciegamente, ni siquiera plenamente. La utilidad debe ser siempre suplementada - guiada- por una visión que se dirija nada menos que al saber, a la agudización del juicio sobre asuntos que no son puramente cuantificables. La utilidad debe ser dirigida por una brújula de la mente suficientemente amplia y comprensiva para ver las direcciones por las que una sociedad se guía, además de bastante extensa para ofrecer un criticismo o aviso referente a qué direcciones son peligrosas o injustas, así como también urge la esperanza, la energía y el apoyo a aquellas orientaciones que son prometedoras. Esto, por supuesto, está en el borde de lo político, dentro del marco del Estado, aunque también afecta al liderazgo, ya sea en negocios, educación, ciencia, cultura, derecho o en la vida espiritual.

[Traducción del inglés por Pablo Badillo O'Farrell]

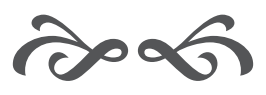

